


\section{WERTE DER DEUTSCHEN HEIMAT}

Veröffentlichungen der Kommission für Heimatforschung

Band 4

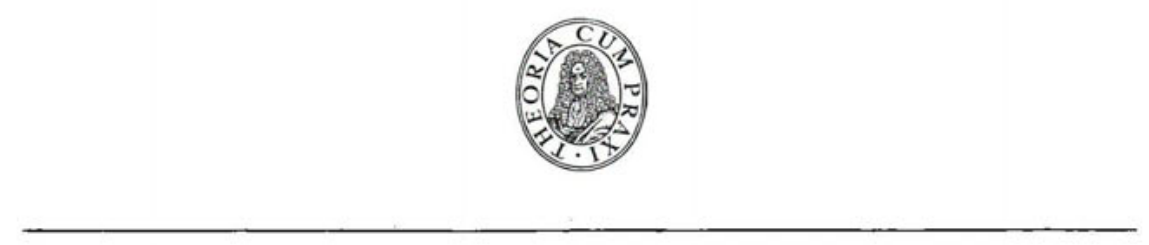

AKADEMIE-VERLAG - BERLIN 


\title{
UM GOTTLEUBA, BERGGIESSHÜBEL UND LIEBSTADT
}

\author{
Ergebnisse der heimatkundlichen Bestandsaufnahme \\ im Gebiet von Gottleuba
}

Bearbeitet in der Arbeitsstelle Dresden nach einem Manuskript von Walter Jobst mit Beiträgen von Heinz Grundig

Mit 25 Abbildungen, 8 Kunstdrucktafeln, t Ubersichtskarte

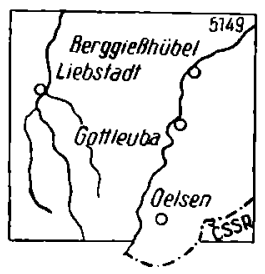


Alle Rechte vorbehalten

Copyright 196r by Akademie-Verlag GmbH, Berlin

Erschienen im Akademie -Verlag GmbH, Berlin W 8, Leipziger Str. 3-4

Lizenz-Nr. 202 - 100/125/61 - Kartengenehmigung des MdI der DDR: Nr 5910

Satz, Druck und Einband: Druckhaus ,Maxim Gorki", Altenburg

Bestellnummer: 2084/4

Printed in Germany

ES 15 D 